Volume, 14, n, 1, ano, 2018

\title{
DESAFIOS DO PROFESSOR HOMEM NA EDUCAÇÃO INFANTIL Um debate a partir do estágio em pedagogia
}

\begin{abstract}
RESUMO O objetivo desta pesquisa é refletir sobre o lócus do homem na educação infantil. A presente pesquisa identificou alguns desafios aos professores homens em estágio, em um curso de Pedagogia do norte brasileiro, ao trabalharem com as crianças pequenas na educação infantil, bem como a partir das falas de professoras mulheres que já atuam nesta faixa de escolarização. O problema central da pesquisa é traduzido na pergunta: quais as dificuldades que encontram os professores da educação infantil? Utilizou-se de questionário e entrevista para coleta de dados e a Análise de Conteúdo como tratamento destes dados. Os desafios da formação e da carreira foram organizados em três dimensões: a primeira dimensão é a tentativa de maior impacto das pesquisas sobre o tema na mudança cultural e organizacional da escola e de seus atores a partir do Projeto Político Pedagógico; a segunda é a continuação do investimento intelectual e de produção de conhecimento relativo à identidade profissional do professor homem na educação infantil, o que leva a discussões sobre as masculinidades e a educação; a última dimensão destaca o papel contínuo da universidade com pesquisa e extensão que culminem em diálogos com as políticas públicas locais, levando-se em consideração as dimensões anteriormente identificadas.
\end{abstract}

Palavras-chave: Professor homem. Educação Infantil. Estágio.

\section{CHALLENGES OF THE TEACHER MAN IN CHILD EDUCATION: A discussion from the Internship in Pedagogy}

\begin{abstract}
The aim of this research is to reflect on man's locus in early childhood education. The present research identified some challenges to the male teachers in the training stage, in a Northern Brazilian Pedagogy course, when working with young children in early childhood education, as well as, from the statements of female teachers who already work in this schooling range. The central problem of the research is translated into the question: what difficulties do the teachers of early childhood education encounter? We used a questionnaire and interview for data collection and Content Analysis as a treatment of these data. The challenges of training and career were organized in three dimensions: the first dimension is the attempt of greater impact of the research on the subject in the cultural and organizational change of the school and its actors from the Political Pedagogical Project; the second is the continuation of the intellectual investment and production of knowledge concerning the professional identity of the male teacher in the child education, which leads to discussions on masculinities and education; the last dimension highlights the university's continuing role in research and extension that culminates in dialogues with local public policies that take into account the previously identified dimensions.
\end{abstract}

Key-words: Teacher man. Child education. Internship.

\section{INTRODUÇÃO}

O presente trabalho objetiva uma reflexão sobre o homem enquanto professor de educação infantil. Bem sabemos, este espaço é predominantemente feminino, por seu turno, o masculino, em certo sentido, seja do ponto de vista da história, da política e do próprio processo pedagógico, não tem nele um lugar de destaque, seja no âmbito social, seja na esfera cultural. Do ponto de vista do interior da escola, as razões históricas da docência no Brasil, 
Volume, 14, n, 1, ano, 2018.

emanam numa visão única, talvez, ingênua e rasteira, tantas vezes enraizada na mera opinião das pessoas, não, no conhecimento científico, investigado e alinhado com os estudos e pesquisas. Entendem os professores e as professoras em sua grande maioria, do norte ao sul dos pais, o cuidado infantil é papel/função da (de) mulher.

No imaginário da maior parte das pessoas, o cuidado na escola de educação infantil se dá em comparação ao cuidado materno, portanto, ligado à mãe, neste sentido, ficando bem representado nessa relação, ou seja, a educação de crianças na escola está configurada à figura da mulher. Contudo, parece complexo e difícil o homem ocupar esse espaço, conforme apresenta Silva (2014):

\footnotetext{
A escola da educação infantil, seus professores e todos os envolvidos na unidade escolar, na rede de ensino, é espaço para se refletir na desconstrução de que esse espaço é feminino e que a presença de um homem é ameaçadora, incompatível com a realidade: um fracassado trabalhador da indústria ou do comércio que tenta a sorte num trabalho mais "leve" de olhar crianças (SILVA, 2014, p. 49).
}

Assim, como na proposição de Silva, (2014) a presente pesquisa pretende desconstruir o imaginário de que essa profissão é especifica de um determinado gênero, obviamente, o feminino, logo, podendo ser exercida tranquilamente por um profissional homem, formado em Pedagogia. É claro, são necessários estudos que reforcem o debate da identidade profissional de homens na educação infantil, pedagogos, em formação inicial e continuada.

A escola tem um papel fundamental nessa temática, no sentido de desconstruir esse preconceito que continua enraizado ao longo do tempo e que necessita ser banido dos sistemas de ensino municipais brasileiros, dada a realidade emergente no contexto atual.

Dentre tantas, a pesquisa aborda algumas dificuldades fundamentais recorrente ao tema e ao objeto de estudo, nesse sentido pergunta-se, quais as dificuldades encontradas pelos professores homens ao atuarem na educação infantil, sejam, estagiários ou docentes. Essa é a problemática que inaugura a pesquisa; uma temática-problema que necessita ser refletida e investigada cuja relevância, estende, sobretudo na região do norte brasileiro, em que, gradativamente, homens vão sendo inseridos no espaço da escola de educação infantil e nos cursos de pedagogia.

A atuação de professores na educação infantil sempre foi tida como um espaço destinado à figura feminina, porém, nos últimos dez anos, os cursos de Pedagogia estão tendo uma quantidade significativa de acadêmicos do gênero masculino em todo o Brasil, embora 
Volume, 14, n, 1, ano, 2018.

esse número seja muito inferior em relação às mulheres. Mas, estes homens professores, não podem ser suprimidos e nem desconsiderados nas produções literárias, em que, comumente, se referem sempre às "professoras" da educação infantil, sem apontar que os homens também estão lá, presentes na escola infantil, como professores.

Historicamente, no Brasil, foram os homens os primeiros professores, logo no início dos cursos intitulado Normal, criado em 1835. Com o tempo, os homens foram se transferindo para outras profissões, por exemplo, para as fábricas, abrindo assim, o caminho para as mulheres. Esse retorno da figura masculina na sala de aula, em especial na educação infantil, nestes últimos anos, tem sido uma tarefa complexa, uma vez que as pessoas da sociedade contemporânea nem sempre, aceitam este fato como algo comum e natural. É natural que a escola, familiares, as próprias crianças - o menino e a menina aceitem a mulher ao homem.

De acordo com Silva (2014), a sociedade determinou que a mulher, carinhosa, afetiva neste sentido, tem ela, a capacidade e a habilidade de educar e formar as crianças. É como se fosse como algo pronto e acabado, parece algo intrínseco a elas, como se fosse algo inato. Por sua vez, em relação ao homem, as pessoas dessa mesma sociedade entendem o homem o como uma pessoa que não sabe dispor dessas características femininas com as crianças, pois, a figura masculina, representa uma imagem poderosa com aspectos brutais. Numa sociedade como a contemporânea é preciso afirma que essa realidade não deixa de ser verdadeira, no entanto, não é que isso que realmente que se espera de um professor da educação infantil.

A partir do momento em que um professor homem assume uma sala de aula, uma turma da educação infantil, esse profissional precisa demostrar para a instituição de ensino e para os pais das crianças que tem competência, aptidão, habilidade e ainda, que a sua sexualidade não é perigosa para as crianças (RAMOS, 2011). Sobre a sexualidade desses professores, muitas pessoas pensam que se um homem escolhe dar aulas para crianças, ele é homossexual ou até mesmo pedófilo. E,

Para serem aceitos pela comunidade escolar, os professores do sexo masculino passam pelo crivo e pela vigilância dos adultos, especialmente quando a função no interior da instituição infantil exige a execução das funções relacionadas ao cuidado das crianças (RAMOS, 2011, p.61). 
Volume, 14, n, 1, ano, 2018.

Corroboram os debates e as reflexões Silva (2011), Gonçalves; Antunes (2015), Gonçalves; Penha (2015), Gonçalves et al. (2015), Silva (2015), Gonçalves; Faria; Reis (2016) e Faria (2016).

\section{METODOLOGIA E PROCEDIMENTOS}

Os dados foram coletados de entrevistas realizadas com professoras da educação infantil e de questionários aplicados a estagiários homens em escolas de educação infantil.

As professoras mulheres participantes da pesquisa (cinco, no total) pertencem a três escolas: o Centro Municipal de Educação Infantil Irmã Lucília (CMEI) e a Cooperativa Educacional de Pais de Arraias (CEPAR), ambas localizadas no município de Arraias (TO); a terceira escola, a Escola Municipal Rainha da Paz é situada no município de Paranã (TO). Ambas as cidades encontram-se no sudeste do estado do Tocantins.

A entrevista seguiu um roteiro de 4 (quatro) perguntas sobre professores homens na educação infantil, o cuidar e o educar das crianças sob a docência deste possível professor e profissional pedagogo. As entrevistas foram gravadas e em seguida transcritas.

Os questionários foram aplicados com 10 (dez) acadêmicos do $9^{\circ}$ período do curso de Pedagogia da Universidade Federal do Tocantins, Câmpus Arraias, que realizaram o Estágio Supervisionado na Educação Infantil, sendo que somente 8 (oito) desses entregaram o questionário respondido, no qual se solicitava que relatassem suas experiências vivenciadas no estágio, enquanto homens em um espaço associado à figura feminina.

Estes dados passaram pela Análise de Conteúdo, segundo Silva (2012) que organiza uma estrutura de análise, a partir de Laurence Bardin.

\section{RESULTADOS E DISCUSSÃO}

\subsection{Elementos que se sobressaem nas entrevistas com professoras e estagiários homens}

Três categorias para os resultados, a primeira: a feminização na educação infantil, a segunda: a presença de homens na educação infantil e, a terceira: a percepção/preconceitos. Todas elas foram previamente organizadas a partir do referencial da pesquisa, brevemente explicitado na introdução deste artigo a fim de serem tópicos de fundamento de partida para identificação de elementos justificáveis nas respostas aos questionários e às entrevistas das professoras participantes na pesquisa, seguindo a metodologia de Silva (2012). 
Volume, 14, n, 1, ano, 2018.

A categoria, feminização na educação infantil, ainda está muito presente no âmbito educacional da educação infantil, sem dúvida, é possível constatar nos relatos de boa parte dos participantes que, para atuar na educação infantil, o profissional precisa apresentar características como jeito próprio, um estilo próprio, tipo vocacional, de acordo com o vocabulário coloquial da pedagogia, ou seja, os professores precisam ter essa qualidade, como fosse algo inato. Sem essa capacidade, jamais o professor homem pode educar uma criança, ou mesmo, lidar com a mesma, isto é, tem que ter características particularmente dominadas pelas mulheres, como já se referiu na introdução deste artigo. E é interessante que os próprios estagiários homens construam estas colocações e as têm para si o que gera, antecipadamente, alguma insegurança à ida ao campo de Estágio, em uma escola de educação infantil, um lugar próprio de mulheres.

O Estagiário 3 afirma que,

[...] enquanto professor homem na educação infantil, no estágio, acredito que não tenho muito jeito nessa área [..] mais certo seria [...] uma professora mulher.

A Professora 1 confirma também a mesma proposição, ainda que perceba, seguramente, que as concepções sobre isso estão em fase de mudança:

[...] por mais que esteja havendo mudança... ainda vejo a professora como a única capaz de atuar na educação infantil [...].

Silva (2014, p.36) contraria esta opinião generalizada por estagiários e professoras, afirmando que "ser um educador, professor, na escola da infância é profissão, é oficio, é ocupação. Oficio e ocupação dados por uma habilitação conferida por uma instituição legitimada social e juridicamente".

A base fundamental da educação infantil é o educar e cuidar. Entretanto, percebe-se, que algumas professoras, participantes da pesquisa, ainda veem esta etapa da educação básica, como um espaço destinado somente para o cuidado das crianças e deixam de lado o educar, e atrelam tudo isso à figura da mulher. E, assim, determinando que somente o gênero feminino está apto para exercer tal função educativa de atuar na educação infantil, pelo fato de serem mulheres e exercerem o papel da maternidade, constroem um ideal de que a presença de homens é prejudicial ao "bom" andamento da educação de crianças, ou seja, apontam para a 
Volume, 14, n, 1, ano, 2018.

inadequação do gênero masculino para esta função. Consequentemente, assumem que somente a mulher é que sabe e pode transmitir afeto, carinho e amor às crianças, como se o professor homem não fosse capaz de demonstrar os mesmos sentimentos, atitudes, embora não das mesmas formas que as mulheres, como bem apresenta Silva (2014).

Isso pode ser conferido nos relatos a seguir.

\title{
Professora 1
}

[...] acho que, pelo fato de demonstrar mais afeto de uma mãe na hora de dar carinho, amor $[\ldots]$.

[...] o professor é tudo, babá, mãe, tia, médica, então ele precisará mostrar para o aluno que é capaz de fazer isso tudo.

\section{Professora 2}

[...] a criança nessa faixa etária da educação infantil necessita de cuidados diferenciados, que já são natos do gênero feminino.

\section{Professora 4}

[...] esse papel de mãe que determinou que a mulher está apta a ser professora da educação infantil.

As professoras, em suas colocações sobre o tema, posicionam-se como pais/responsáveis, admitindo inclusive, que os pais de seus alunos(as) pensam da mesma forma que elas, ou seja, apostam que os pais/responsáveis também pensam como elas e estão unidos na mesma ideia de rejeição e inadequação de um homem professor de crianças nessa faixa de escolarização. Uma colocação predominante é que as professoras na educação infantil devem ser mais cuidadoras, mais afetuosas; veem, assim, as instituições de ensino para crianças como uma extensão do lar.

Silva (2014) rebate essa concepção argumentando que:

\begin{abstract}
O professor/ a professora de educação infantil não é um cuidador ou cuidadora, nem babá, como alguns pais se referem ainda. Ele / ela é alguém que exerce uma profissão. Recebeu formação para isso. Foi aprovado num concurso público ou passou por uma entrevista que o habilita a exercer uma função: a função de ensinar na primeira infância. Referimo-nos, portanto, a uma pessoa que trabalha. Está envolvida em práticas de ensino e aprendizagem, cuidado e desenvolvimento humano (SILVA, 2014, p.40).
\end{abstract}

Em parte dos depoimentos das professoras, verifica-se que elas apontam os pais das crianças como os principais responsáveis por não aceitarem professores homens atuando na 
Volume, 14, n, 1, ano, 2018.

educação infantil, devido ao receio desses profissionais terem que cuidar da higiene corporal das crianças.

Com esses relatos, é possível notar a tentativa dessas professoras de justificarem a quase inexistência do gênero masculino atuando na educação infantil, sobretudo no contexto do sudeste tocantinense, e suas resistências, sem nenhuma concepção ou base nas teorias pedagógico-educacionais.

\section{Professora 2}

[...] os pais pensam que o professor homem não tem habilidade para atender todas as necessidades pessoais das crianças, necessidades essas como higiene corporal e outras.

\section{Professora 4}

[...] as mães não ficam tranquilas em entregar seus filhos tão frágeis, ali, na mão de um homem que a gente não tem laços sanguíneos; nesse momento é que se gera esse medo e, consequentemente, essa discriminação.

\section{Professora 5}

[...] mães não querem que suas filhas sejam cuidadas por homens, e sim por mulheres.

Quanto a esta questão do cuidado, é preciso uma mudança de concepção na sociedade como um todo sobre o que seria o cuidar e o educar na educação infantil, pois esse cuidar não pode se reduzir ao cuidado corporal, embora presente e intrinsecamente a ele relacionado. Sayão (2005, p.154) indica que,

[...] uma das grandes dificuldades na compreensão do cuidado na Educação Infantil é a sua vinculação restrita ao corpo, não levando em consideração as intenções, os sentimentos e os significados que estão amplamente correlacionados com o cuidar. Essa visão reducionista de cuidado não pode mais ser concebida [...].

O cuidado corporal das crianças foi determinado pela sociedade como sendo de responsabilidade exclusiva do gênero feminino; o pai, é o provedor, a mulher, cuida da casa e dos filhos. A partir do momento em que um profissional do gênero masculino executa essa mesma tarefa, surgem a contestação, a indagação e a resistência por parte de alguns indivíduos.

São evidentes os preconceitos e estigmas originários de ideias que veem a profissão como eminentemente feminina porque lida diretamente com os cuidados corporais de meninos e meninas. Dado que, historicamente, e como uma continuação da 
Volume, 14, n, 1, ano, 2018

maternidade, os cuidados com o corpo foram atributos das mulheres, a proximidade entre um homem lidando com o corpo de meninos e/ou meninas de pouca idade provoca conflitos, dúvidas e questionamentos, estigmas e preconceitos (SAY ÃO, 2005, p.16).

Os relatos a seguir positivam a docência masculina na educação infantil.

\section{Estagiário 4}

[...] Com isso ao percorrer do estágio fui percebendo que é tão bom trabalhar com crianças que não é somente mulheres que sabem lidar, mas homens também sabem desenvolver esse trabalho com facilidade.

\section{Professora 3:}

[...] o professor homem é um profissional capaz de promover competência no processo de ensino-aprendizagem em qualquer instituição de ensino da educação infantil.

\section{Professora 4}

[...] que é capaz de desenvolver um trabalho excelente, assim como o gênero feminino.

\section{Professora 5}

[...] o professor homem possui formação e capacidade para atuar na educação infantil, às vezes até melhor e mais organizado que muitas professoras.

Porém, ao mesmo tempo, em que esses relatos apontam positivamente a presença do gênero masculino na educação infantil, detecta-se o estranhamento, o receio e a falta de confiança das colegas docentes (gênero feminino), o que é também muito perceptível entre os estagiários, que, apoiando-se em justificativas generalizadas e hipotéticas, de senso comum, perpetuam a máxima da feminização do magistério na educação da criança pequena e, talvez, sem perceber, inconscientemente, desqualificam o homem professor, na educação infantil.

\section{Estagiário 2}

[...] percebi que os pais, principalmente das meninas, tiveram a preocupação de ir até a sala de aula para ver de perto quem estaria ministrando a aula no momento do estágio para suas filhas; se nota que isso não aconteceria se fosse uma professora.

\section{Estagiário 2}

[...] no primeiro dia de aula todos os alunos ficaram me olhando como uma figura estranha, mas com o tempo eles foram acostumando e me dando um respeito de um professor. 
Volume, 14, n, 1, ano, 2018.

Professora 1

[...] ainda não há confiança nos professores homens principalmente para lidar com as alunas do sexo feminino.

Professora 4

[...] vejo um pouco "perigoso" para essas crianças, dependendo do professor.

Sobre essa falta de confiança, competência e habilidade que os professores homens são "acusados" de não possuírem, de certa forma, são encarados por eles como um forte desafio a superar como mostram as pesquisa de Ramos (2011), Gonçalves; Antunes (2015).

Verifica-se, em parte dos depoimentos dos estagiários homens que, mesmo de forma velada, percebiam o preconceito por estarem estagiando em uma sala da educação infantil, como pode ser visto nos seguintes relatos:

Estagiário 2:

[...] Nós estagiários não podíamos levar os alunos no banheiro, trocar suas roupas etc.

Estagiário 5

[...] no estágio pude notar resistência de alguns gestores quanto a liberdade entre eu e as crianças meninas principalmente, por receio ou medo.

\section{Estagiário 8}

[...] Consolar uma criança que estava chorando, dar um abraço, um beijo, por exemplo, [...] são coisas que não podiam acontecer conosco, mas aconteciam naturalmente, como de costume, todos os dias, mas somente com as professoras e as estagiárias.

As professoras afirmam seu preconceito em relação aos professores homens e isto é averiguado quando as mesmas destacam a pedofilia como uma das suas justificativas de resistência à presença de professores homens na educação infantil.

\section{Professora 1}

[...] uma mãe não há de confiar em um homem, mesmo sendo professor, dando banho em sua filha, por exemplo, devido aos casos de pedofilia que tanto vemos hoje.

Professora 3 
Volume, 14, n, 1, ano, 2018

[...] a sociedade não admite essa possibilidade, devido os acontecimentos causados no dia a dia, por exemplo, casos de pedofilia.

\title{
Professora 4
}

[...] é um pouco complicado um professor homem trabalhar na educação infantil, porque trabalhar com a educação infantil, cuidar de crianças bebês até 3 anos é um fato um pouco desajeitado, não que ele não tenha capacidade, mas a gente vê tantas coisas até com [homens] [...] com laços sanguíneos; casos de assédio sexual, a pedofilia com crianças, enfim, que ficamos apreensivas.

Silva (2014) confirma esses posicionamentos em relação aos profissionais homens que escolhem a profissão de lidar com crianças, ou seja, de atuarem na educação infantil como professores, constatando que:

\begin{abstract}
Assim que a figura feminina moldada à mãe, ao carinho, ao afeto vai se firmando no espaço escolar da primeira infância, a ponto de quando do aparecimento de um homem, o fato de causar espanto, causar adversidade dos pares, quase sempre acusando na consciência de senso comum das pessoas como um suspeito pedófilo ou um homem que não gosta de mulheres (SILVA, 2014, p.47).
\end{abstract}

Vê-se assim, a necessidade de uma formação em duas frentes para se tratar da questão dos medos e resistências em relação aos professores homens na educação infantil: a primeira frente é na formação continuada, nas redes de ensino municipais; a segunda é na formação inicial, seja a partir de disciplinas na temática de gênero e sexualidade ou a partir de oficinas de experimentação ou laboratórios de práticas pedagógicas em sexualidade, durante os Estágios dos estudantes, realizados na educação infantil.

O importante é que se fale do assunto, que se conscientize, tanto a iniciantes da carreira quanto aos professores(as) e seus superiores, gestores de unidade e do sistema educacional, que a diversidade, em seu sentido amplo, e a diversidade sexual, em seu sentido restrito, é um tema para se refletir e gerar mudanças outras que se distanciem dos preconceitos, discriminações, atitudes generalizadoras negativas, que nada contribuem para a cidadania e não combinam em nada com o aspecto democrático.

Estas categorias macro, latentes, evidentes, que surgiram na pesquisa, foram acompanhadas de outras categorias que emergiram silenciosamente, ocultamente, mas que estão presentes no dia a dia do estágio dos homens professores e no dia a dia das mulheres professoras, responsáveis por turmas de educação infantil. 
Volume, 14, n, 1, ano, 2018

\subsection{Categorias implicitamente encontradas nas falas de estagiários homens e professoras}

Nas falas de boa parte dos sujeitos pesquisados é possível observar alguns detalhes que ficaram nas "entre linhas", como na fala do estagiário 4

\section{Estagiário 4:}

[...] $\mathrm{Na}$ semana de observação fiquei observando e cultivando o carinho de cada criança, observando a professora trocando fraldas, colocando as mesmas para dormir, dando banho, e entre outras tarefas. Nas outras semanas que foram de Regência somente ajudei a professora a colocar as crianças para dormir, ajudei distribuir o lanche.

O estagiário 4, no início do seu relato, diz que durante o seu estágio no maternal ele não sofreu preconceito, porém ao analisar o seu depoimento fica claro que na maior parte do seu estágio ele foi apenas um "ajudante" da professora, pois em nenhum momento ele teve um contato direto com as crianças como regente na sala de aula. Não fora permitido.

Outro caso de relatos implícitos que se pode observar é o da professora P1 quando diz:

\section{Professora P1}

[...] O professor homem para trabalhar com a educação infantil [...] vai ter que ter um jogo de cintura, pois o aluno depende muito do professor na sala, o professor é tudo, babá, mãe, tia, médica, então ele precisa mostrar para o aluno que é capaz disso tudo. $\mathrm{O}$ aluno tem que ter confiança nele, mesmo sendo homem.

Neste depoimento se verifica que a professora diz que não devemos encarar a presença de um professor homem na educação infantil com receio, e que temos que vê-lo como um profissional responsável e capacitado para atuar na área. Porém, quando ela disse "mesmo sendo homem", a professora contradiz a sua fala inicial, pois esse "mesmo" pode ser encarado como um preconceito implícito com o gênero masculino.

Durante a entrevista com as professoras, era notável o desconforto de algumas quando eram-lhes apresentadas as questões do roteiro da entrevista. No momento em que a pesquisadora realizava as perguntas, as entrevistadas pediam certo tempo para que pudessem refletir sobre elas. As faces das entrevistadas, após cada pergunta, revelavam também como o tema lhes era caro. Essas atitudes, em seu conjunto, traz a evidência de que as mesmas tinham um receio de responder de imediato e falar sobre os homens professores.

A presença da entrevistadora mulher facilitou o desprendimento das professoras, o que contribui para se detectar elementos significativos na pesquisa que não seriam possíveis, caso 
Volume, 14, n, 1, ano, 2018

a entrevista fosse conduzida por um pesquisador iniciante ou do sexo masculino, da área da educação.

\section{CONSIDERAÇÕES FINAIS}

O conjunto das categorias elaboradas na pesquisa indica a organização de alguns desafios à formação inicial em estágio, em um curso de Pedagogia, bem como em relação à carreira de professores homens na educação infantil, conforme descritos abaixo:

- Desafio 1. Maior esclarecimento, mais estudos de impacto na educação básica, a partir das Diretrizes em Direitos Humanos, que abordem a profissionalidade docente masculina atuando tanto à frente da formação inicial como à frente da formação continuada de professores da educação infantil. Soma-se a isso, a necessidade de um projeto político pedagógico esclarecedor aos pais das crianças, desde o momento da matrícula, junto, obviamente com reuniões de pais/responsáveis, para se discutir sobre a relevância de ser eliminada toda forma de preconceito e discriminação de gênero nas relações entre os atores da escola e os pais/responsáveis das crianças pequenas.

- Desafio 2. O rompimento dos medos e da insegurança por parte dos estagiários homens e professores homens, no sentido de firmação da identidade docente masculina, considerando as masculinidades e sua relação complementar com as feminilidades, organizando conexões de conceituações e concepções de docência na escola infantil, sob a perspectiva da igualdade de gênero, o que leva a considerar o respeito e a postura intelectual e ética, principalmente para se tratar dos temas da homossexualidade e da população LGBT Lésbicas, Gays, Bissexuais e Transsexuais. Trata-se de uma identidade profissional masculina na educação infantil e o seu adentrar ao campo da educação de crianças pequenas; trata-se de profissionalização entre pares (as mulheres professoras), considerando sempre a máxima da relação que transforma $\mathrm{o}(\mathrm{s})$ conflito(s) em oportunidades para crescimento pessoal, profissional e, sobretudo, organizacional, que reflete o desenvolvimento das crianças e a qualidade de ensino, nesta primeira etapa da Educação Básica. Isso garantiria, obviamente, com o apoio dos gestores dos sistemas e das unidades escolares, a contrapartida do sentimento de segurança e satisfação dos pais/responsáveis, ao compreenderem a diversidade, em seu sentido mais amplo, sobretudo, este, o de ter um professor homem na escola de educação infantil, que é tão profissional e tão competente quanto à professora mulher, e que não constitui nenhuma "ameaça" às crianças pequenas como vem demonstrando essa questão no 
Volume, 14, n, 1, ano, 2018.

dia a dia da escola. Defende-se, neste texto, que a identidade do professor homem na educação infantil deve perpassar o estudo da sociologia das profissões, devendo ser um tema obrigatório na formação inicial em cursos de Pedagogia e temas de debates nos sistemas de ensino municipais que coordenam escolas de educação infantil.

- Desafio 3. Continuidade de pesquisas e extensão sobre a presença de professores homens na educação infantil, perpassada pelas relações de gênero, trabalhos esses capazes de gerar diálogos e aproximações com as políticas públicas locais. Considerando o aumento da presença de homens professores em formação nos cursos de Pedagogia, ainda que gradativo, sobretudo no sudeste tocantinense, esse desafio 3 é mais que urgente e necessário e se supõe, pela produção de conhecimento existente sobre o tema, que a realidade do sudeste tocantinense não é muito diferente dos demais municípios brasileiros. Conclui-se que, nesse desafio último, a universidade irá promover um impacto social relevante, ao considerar as diversidades existentes em todos os âmbitos sociais e contribuir, assim, para que as relações de gênero sejam marcadas pela igualdade e qualidade, saudavelmente vividas, com cidadania e democracia amplas.

\section{REFERENCIAS}

FARIA, T.C.L. Magistério no Brasil: profissão feminina e masculina. Cadernos da Pedagogia, São Carlos, ano 10, v.10, n.19(10), p.40-51, jul./dez., 2016.

GONÇALVES, J.P. et al. Professores homens na educação infantil: aceitação e receio dos familiares que vivenciam essa experiência. Pesquisa em foco, São Luís, v. 20, n.2, p. 136$154,2015$.

GONÇALVES, J.P.; ANTUNES, J.B. Memórias de professores homens que trabalhara como docentes de educação infantil e suas representações sociais. Interfaces da Educação, Paranaíba, v. 6, n. 16, p. 134-253, 2015.

GONÇALVES, J.P.; FARIA, A.H.; REIS, M.G.F.A. Olhares de professores homens de Educação Infantil: conquistas e preconceitos. Perspectiva, Florianópolis, v. 34, n.3, p. 9881014, set./dez., 2016. 
Volume, 14, n, 1, ano, 2018.

GONÇALVES, J.P.; PENHA, N.R. Professor homem na educação infantil: o olhar de acadêmicos e alunos egressos do curso de pedagogia. Zero-a-seis, Florianópolis, v.17, n.32, p. 170-192, jul-dez, 2015.

RAMOS, J. Um estudo sobre os professores homens da educação infantil e as relações de gênero na rede municipal de Belo Horizonte - M.G. 140f. 2001. Dissertação. (Mestrado em Educação). Programa de Pós-Graduação em Educação, Pontifícia Universidade Católica de Minas Gerais, Belo Horizonte, 2011.

SAYÃO, D. T. Relações de gênero e trabalho docente na educação infantil: um estudo de professores em creche. 273f. 2005. Tese. (Doutorado). Centro de Ciências da Educação, Universidade Federal de Santa Catarina. Florianópolis, 2005

SILVA, A. C. Entrevista. In: ELLIOT, L. G. (org.). Instrumentos de avaliação e pesquisa: caminhos para construção e validação. Rio de Janeiro: Wak, 2012.

SILVA, B.L.B. A presença de homens docentes na educação infantil: lugares (des) ocupados. 107f. 2015. Dissertação. (Mestrado em Educação). Programa de Pós-Graduação em Educação, Universidade Federal do Rio Grande do Norte, Natal, 2015.

SILVA, C. R. Docência masculina na educação infantil: impressões de um iniciante. Gênero e raça em discussão. Jundiaí, SP: Paco Editorial, 2014.

SILVA, C.R. Professor homem, negro na escola da infância: reflexões e apontamentos de um iniciante. Temas em Educação e Saúde, Araraquara, v.7, p. 125-150, 2011. 